\title{
THE EXCRETION OF UREA IN NORMAL MAN AND IN SUBJECTS WITH GLOMERULONEPHRITIS ${ }^{1}$
}

\author{
BY HERBERT CHASIS AND HOMER W. SMITH \\ (From the Departments of Medicine and Physiology, New York University College of \\ Medicine, New York City)
}

(Received for publication February 8, 1938)

It is well known that the magnitude of the urea clearance in man is related to the rate of water excretion (urine flow), this relationship being commonly expressed in terms of the "standard" and "maximum" clearances of Möller, McIntosh and Van Slyke (20). But the actual physiological basis for the relationship is undetermined. It is recognized that the rate of excretion of urea in the higher animals is considerably less than would be expected on the basis of glomerular filtration: this was first indicated by Mayrs (19) from a comparison of the rates of excretion of various substances in the rabbit, and later substantiated for this animal by the investigations of MacKay and Cockrill (17), for man by Rehberg (25), for the dog by Jolliffe and Smith (16), the seal by Smith (32), the sheep by Shannon (27), and the chicken by Pitts and Korr (23).

Rehberg (25) and Holten and Rehberg (13) suggested that the relationship between urea clearance and urine flow in man is owing to the passive diffusion of urea across the tubules in consequence of the creation of a concentration gradient by the reabsorption of water from the glomerular filtrate. Van Slyke, Rhoads, Hiller, and Alving (37) and Gordon, Alving, Kretzschmar, and Alpert (11) have observed in dogs with explanted kidneys that, although over any considerable period of time the urea clearance bears a fairly constant relationship to the rate of filtration, the fraction reabsorbed may vary markedly from moment to moment, but the reasons for this variation are unknown.

In the absence of any substantial evidence to the contrary, it may be assumed that the deficit

1 This paper is based on a thesis submitted by the first author in partial fulfillment of the requirements for the degree of Doctor of Medical Science at New York University. between the urea clearance and the filtration rate in man is due entirely to tubular reabsorption, but in view of Shannon's (27) observations on the $\mathrm{dog}$, it is clear that this reabsorption is not related in a simple manner to the rate of water excretion.

No systematic observations have been recorded on the relationship of the urea clearance to the rate of glomerular filtration and of water excretion in man. Numerous investigators have examined the simultaneous creatinine and urea clearances in normal man and in subjects with acute or chronic diffuse glomerulonephritis, among whom may be mentioned Rehberg (24, 25), Holten and Rehberg $(13,14)$, Cope (6), Hayman, Halsted, and Seyler (12), Ellis and Weiss $(8,9$,$) , Cambier (5), Covian and Rehberg (7),$ Winkler and Parra (38, 39), Bjering (3) and Bing and Bjering (2). The most important facts established by these investigations are that the urea clearance (with few questionable exceptions) is less than the creatinine clearance, and that in renal disease the two clearances are reduced in a roughly parallel manner. A few instances have been recorded in which the urea clearance was excessively reduced, relative to the creatinine clearance, indicating, as Rehberg (25, 13) suggests, increased permeability of the tubules and abnormal back diffusion of urea.

In view of the evidence against the acceptance of the creatinine clearance as a measure of glomerular filtration in man $(26,33)$, in view of the importance of the possibility of increased permeability of the tubules in glomerulonephritis, and in view of the inadequacy of our knowledge concerning the mechanism of excretion of urea, it was felt that a study of simultaneous inulin and urea clearances in normal subjects and in subjects with renal disease would be valuable.

The present report includes observations on 10 subjects with normal renal function and 22 sub- 
jects with acute or chronic glomerulonephritis. ${ }^{2}$ All subjects were patients on the Medical Service of the Third (New York University) Division of Bellevue Hospital. The normal subjects had been admitted for treatment of diseases other than those of the genito-urinary or cardiovascular system. They gave no history of renal disease and at the time of examination they had apparently normal renal function. After convalescence they volunteered to act as subjects for this study. They were under the supervision of a nurse engaged in an investigative capacity and they were given a mixed diet containing approximately 225 grams of carbohydrate, 110 grams of fat and 70 grams of protein, with an adequate supply of minerals and vitamins. They received no drug therapy during the course of observation. Three normal subjects were chosen for a special examination of the urea clearance in relation to the rate of urine excretion. In each series of observations on these subjects, clearance determinations were made over as wide a range of urine flow as possible. The subject was hydrated by the administration of 3 liters of water daily for 1 to 3 days previous to observation; on the morning of observation he received no breakfast but drank 2 liters of water, the last water being administered at least 45 minutes before the first clearance period. Since it was impossible to obtain low urine flows after diuresis, these clearances had to be determined at essentially constant urine flows during moderate dehydration effected by abstinence from water for 48 to 60 hours. In general, each series of observations continued over a period of two and one-half hours, the urine collection periods varying according to the rate of urine flow from 7 to 25 minutes. The general methods of examination of all subjects, the administration of inulin by constant intravenous infusion, the collection of urine and methods of chemical analysis have been described by Smith, Goldring, and Chasis (34).

2 A preliminary report has been made on the inulin and phenol red clearance, etc. in these nephritic subjects by Goldring and Smith (10) and a full report will be made later. This report constitutes a full discussion of the excretion of urea in these subjects, and we are indebted to Dr. Goldring for the opportunity to present these observations.
NORMAL SUBJECTS

\section{Effect of inulin on urea clearance}

In order to determine whether the administration of inulin has any effect on the urea clearance, we have examined the latter in one subject (C.B.) in 34 periods without, and 39 periods with, simultaneous inulin clearances. These observations will not be reported in detail, but it may be said that when the urea clearance is plotted against urine flow the two sets of data, with and without inulin, are entirely superimposable. It is concluded that neither inulin nor our method of administering it by constant intravenous infusion changes the specific relationship of the urea clearance to the rate of urine flow.

\section{Relation between filtration rate and urine flow}

We present for examination of this question 130 simultaneous inulin and urea clearances in 3 normal subjects (E. B., T. G., and C. B.) who were the object of special study, and 95 simultaneous inulin and urea clearances in 7 other normal subjects, ${ }^{3}$ the latter being examined when the rate of urine formation was falling or had attained a moderately steady rate after water diuresis. The average inulin clearance for the individuals in this group, excluding Subject C. B., ${ }^{4}$ ranged from 110.0 to 128.8 , with a mean of 120.5 , compared to the mean normal value of $122.5 \mathrm{cc}$. per $1.73 \mathrm{sq}$. m. per minute (34).

There is a slight correlation between the rate of filtration and the urine flow, as will be seen in the detailed data on Subject E. B. given in Figure 1 , in the data on Subject T. G. which have been recorded by Smith (Figure 6 (33)) and in the mass data on all subjects given in Figure 2. It is admittedly difficult to interpret this correlation, since several incidental factors may in-

\footnotetext{
8 These 7 subjects are mentioned in the summary presented in Table III of Smith, Goldring and Chasis (34).

4 Subject C. B. although giving no history of renal disease, showed average urea and inulin clearances of about 50 and $95 \mathrm{cc}$. respectively; these values lie outside the range of normal values, as observed by Smith, Goldring and Chasis (34). He also showed anomalous renal function in that it was impossible to raise his urine flow by extreme water diuresis above $8.0 \mathrm{cc}$. per minute. But in respect to the urea/inulin clearance ratio he behaved like the other normal subjects examined here, and data upon him are included in Figure 4.
} 


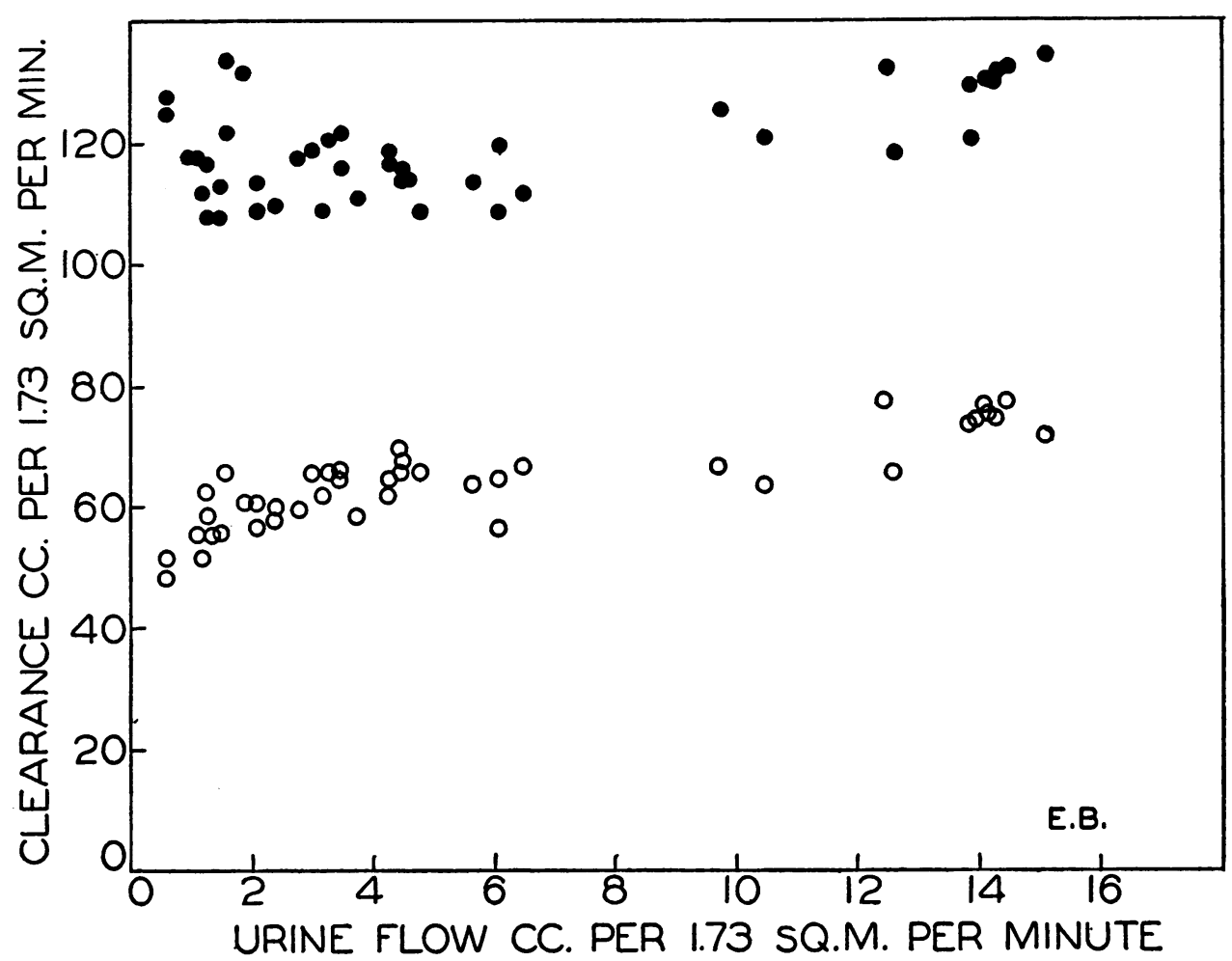

Fig. 1. 42 Simultaneous Inulin (dots) and Urea (circles) Clearances on Subject E. B. during Falling or Constant Urine Flows

Each datum is a single clearance period.

fluence the filtration rate. For example, we are inclined to attribute the evident tendency for the filtration rate to increase above the average value at high urine flows to hydremia, increased circulation, etc., attending the administration of large quantities of water, and the tendency for the filtration rate to fall below the average value at low urine flows to extrarenal factors such as anhydremia, oligemia, decreased cardiac output, or vasomotor effects of dehydration. We recognize that when the filtration rate can, under basal conditions, vary in a single individual by $\pm 10 \mathrm{cc}$. per minute, it would be hazardous to conclude that slight changes in this process have no physiological relationship to urine flow; but in the same subject at the same filtration rate the urine flow may vary on different occasions from 1.0 to $16 \mathrm{cc}$. per minute, or at the same urine flow the filtration rate may vary from 110 to $130 \mathrm{cc}$. Such correlation as may exist at normal filtration rates appears to be incidental and to have no physiological relation to urine flow within the range of
0.5 to $20 \mathrm{cc}$. per minute. This conclusion is in agreement with the lack of correlation between the creatinine clearance and urine flow, as demonstrated by Holten and Rehberg (13), Covian and Rehberg (7) and others. (We have not examined the filtration rate at urine flows below $0.5 \mathrm{cc}$. per minute since such low flows cannot be obtained without excessive dehydration, particularly when saline is being given by constant intravenous infusion.)

\section{Possible conversion of urea to ammonia}

Since urea is completely filtrable from the plasma, the difference between the urea clearance and the filtration rate must be owing to removal of urea from the glomerular filtrate. The possibility that the deficit in the urea clearance in acidosis is a result of conversion of filtered urea to ammonia has been disproved in the dog by Pitts (22) and Alving and Gordon (1), though whether this is true for man is uncertain (36). That such conversion does not contribute to the 


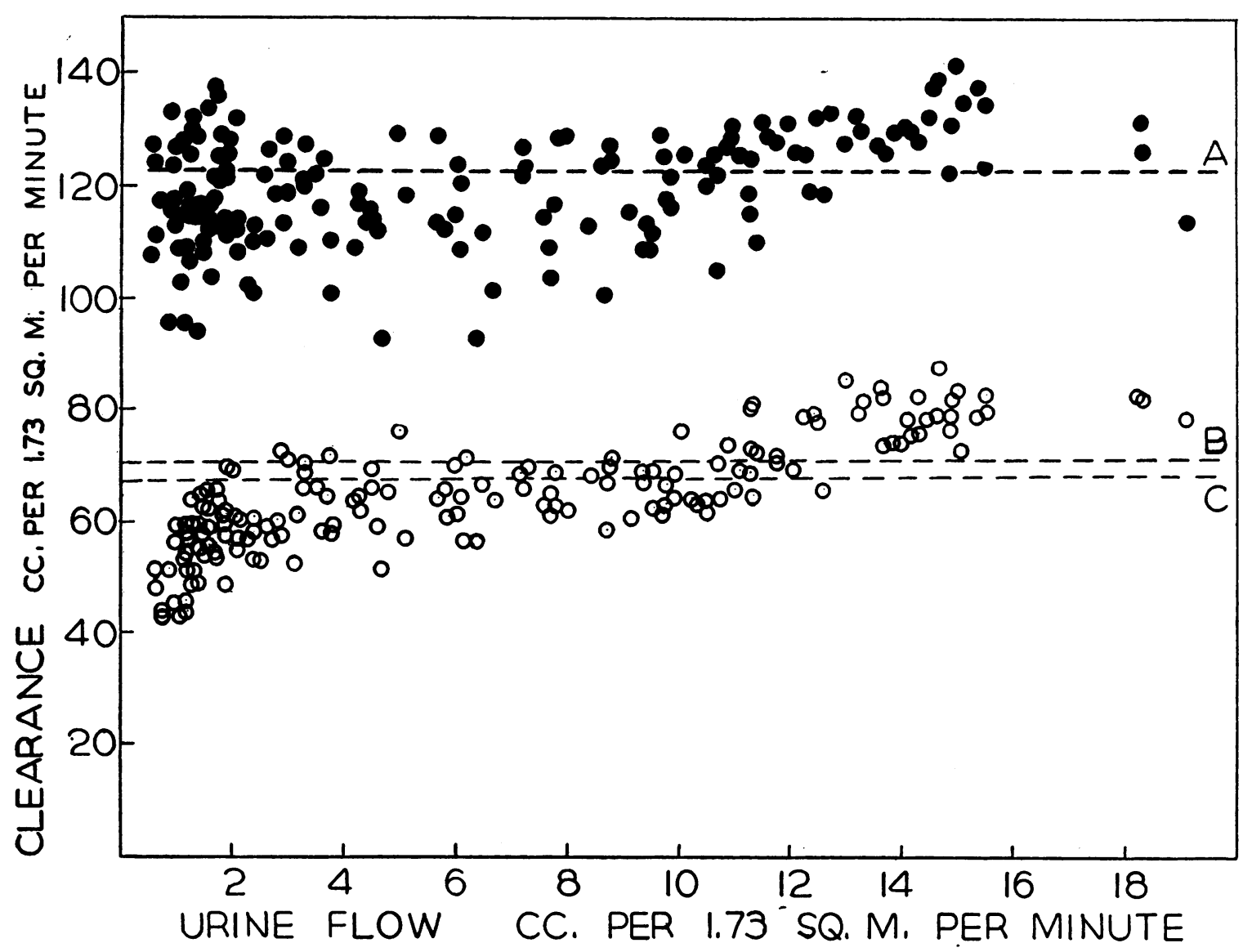

Fig. 2. 186 Simultaneous Inulin (dots) and Urea (circles) Clearances in 9 Normal Subjects during Falling or Constant Urine Flows

Each datum is a single clearance period. Line $A$ : mean plasma inulin clearance $(122.5 \mathrm{cc}$.) in normal man (34) ; line $B$ : mean plasma urea clearance $(70.5 \mathrm{cc}$.) reported by Smith, Goldring and Chasis (34); line $C$ : mean plasma urea clearance $(67.5 \mathrm{cc}$.) calculated from Möller, McIntosh and Van Slyke's (20) value for whole blood, assuming 60 per cent plasma.

difference between the urea and inulin clearances in normal man is indicated by the small amount of $\mathrm{NH}_{3}$ excreted normally; we have demonstrated this specifically by 14 observations on Subject T. G., which show that the urea + ammonia $\mathrm{N}$ clearance is not significantly greater than the urea clearance, either at high or low urine flows.

\section{Reabsorption of urea}

In discussing the reabsorption of urea it is necessary, for reasons which will be apparent, to divide the data into two categories; first, clearances determined when the urine flow is decreasing or has reached a constant value, and second, clearances determined when the urine flow is increasing in consequence of water diuresis.
Inspection of the absolute urea clearance, as portrayed in Figures 1 and 2, shows that there is a progressive increase in the urea clearance as the urine flow increases from low to high values. This is owing in part to the increase in glomerular filtration and in part to diminished reabsorption. Variations in the latter can best be examined by considering the urea/inulin clearance ratio, since 1 - urea/inulin clearance ratio gives directly the fraction of filtered urea which has been reabsorbed. For the examination of the effect of urine flow upon this reabsorbed fraction it is convenient to relate the latter to the $U / P$ ratio of inulin, since this ratio expresses the degree to which the glomerular filtrate has been concentrated by the reabsorption of water. The data on 


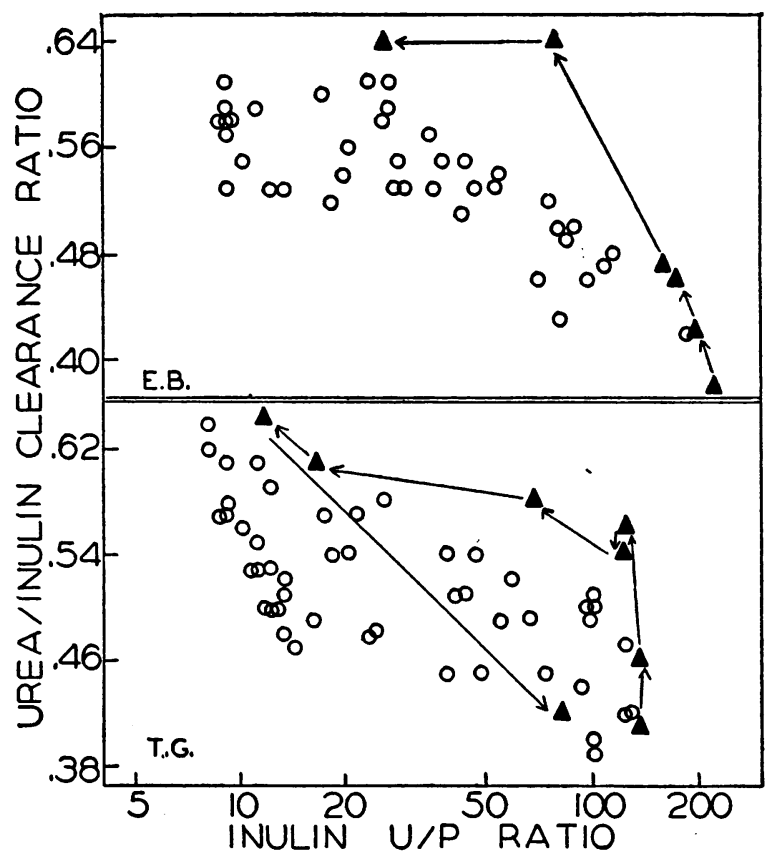

Fig. 3. The Urea/Inulin Clearance Ratio in Subjects E. B. and T. G. in Relation to the Degres of Concentration of the Glomerular Filtrate as Indcated by the Inulin U/P Ratio.

Each point is a single clearance period. The circles are observations on falling or constant urine flows, and the triangles are observations immediately after the administration of $1500 \mathrm{cc}$. of water.

Subjects E. B. and T. G. are presented in this manner in Figure 3.

At inulin U/P ratios of 6 to 10, which are the lowest obtainable in normal man during water diuresis (i.e., at urine flows of 12 to $20 \mathrm{cc}$. per minute), the urea/inulin clearance ratio does not on the average rise above 0.60 ; i.e., at maximal diuresis 40 per cent of the filtered urea is reabsorbed. As the $U / P$ ratio of inulin increases (i.e., as the urine flow decreases), the urea/inulin clearance ratio decreases, showing that a larger fraction of filtered urea is reabsorbed at low than at high urine flows. Although a fairly regular relationship exists between the log of the inulin $\mathrm{U} / \mathrm{P}$ ratio and the fraction of urea reabsorbed, the large scatter of the data suggests that the reabsorptive process is influenced by factors other than the ultimate degree of concentration of the glomerular filtrate. Two such subsidiary factors will be indicated later.
The effects of rising urine flow on the urea/ inulin clearance ratio were examined in three subjects. Observations on Subjects E. B. and T. G. are shown by the solid triangles in Figure 3 . (For similar observations on Subject C. B. see Figure 23 (33).) Abrupt acceleration of urine flow leads to an increase in the urea/inulin clearance ratio, this increase being out of proportion to the anticipated effect of changing inulin $U / P$ ratio, as observed when the urine flow is decreasing or constant. This transitory elevation of the urea clearance, relative to the inulin clearance, is probably identical in origin with the similar phenomenon in the dog (27). It can be elicited both at low and intermediate urine flows, and by the intravenous administration of hypertonic sodium sulphate; and it may occur after the administration of water even though the decrease in inulin $\mathrm{U} / \mathrm{P}$ ratio is negligible. It does not appear to be a result of error in calculating clearances introduced by dead space in the tubules, ureters, or bladder, since the plasma concentration of both inulin and urea was practically constant during these observations; the effect of flushing out dead space on the $U / P$ ratio of both substances should therefore be identical

We feel justified, in considering the problem of urea reabsorption, in assuming that the relationship between the inulin and urea clearance as observed during falling or constant urine flow represents the primary physiological relationship, and we set aside the elevation of the urea clearance during acceleration of the urine flow as a subordinate phenomena which cannot profitably be discussed at this time.

In the upper part of Figure 4 there is presented a mass plot of data on the 10 normal subjects examined by us. The line $B$ represents the best straight line that can be drawn through these data, excluding the points at the extreme right. In considering the significance of this line it must be recognized that the lowest inulin $U / P$ ratios observed by us in normal man at or after the peak of water diuresis, range from 10 to 6 (i.e., urine flows of 12 to $20 \mathrm{cc}$. per minute). The highest inulin $U / P$ ratio obtainable with our technique of examination (i.e., with intravenous saline at 4.0 cc. per minute) is about 200 (urine flow $=0.6 \mathrm{cc}$. per minute), though much higher ratios can be 


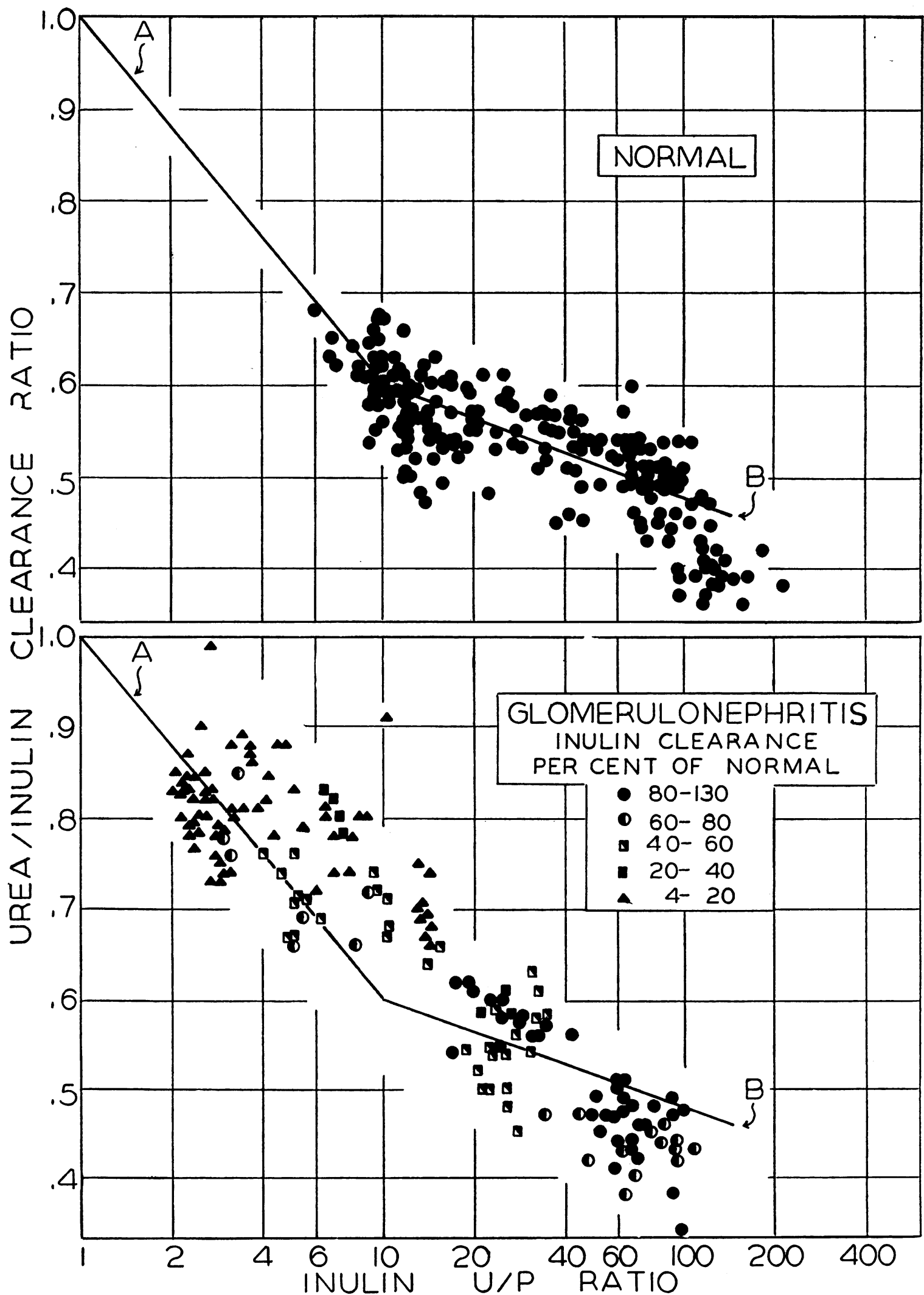


obtained without infusion. ${ }^{5}$ Except for slight differences in slope, line $B$ corresponds very closely to the recent data of Shannon (29) on Dogs $C$ and $G$ (which appear to be typical), the urea/inulin clearance ratio in these two dogs and in our data having a common value of 0.56 at an inulin $U / P$ ratio of 20 . So it may be said that between inulin U/P ratios of 6 and 200 (urine flows of 20 and $0.6 \mathrm{cc}$.) man and dog behave so nearly alike in respect to the reabsorption of urea that the underlying causes may be considered to be essentially the same in both species.

Shannon $(27,29)$ has presented arguments against the belief that the reabsorption of urea in the dog is owing to a single process of passive diffusion determined by the degree of concentration of the glomerular filtrate and the time of contact of the tubular urine with the renal tubules, as calculated from the final composition of the urine. He has recently shown that when diuresis is induced by the continuous intravenous infusion of glucose, $\mathrm{Na}_{2} \mathrm{SO}_{4}$, or urea, the urea/inulin clearance ratio rises towards 1.0 , following the path indicated by line $A$ in Figure 4. At inulin $\mathrm{U} / \mathrm{P}$ ratios of 1.5 to 2.0 (urine flows of $50 \mathrm{cc}$. per minute in a $20 \mathrm{kgm}$. dog) he has obtained urea/inulin clearance ratios as high as 0.945 .

We have not attempted to make observations during forced diuresis in man, but since the excretion of urea in dog and man are so similar in all other respects, there is every reason to believe that the human kidney would respond in the same manner as the dog kidney. We therefore present the two lines, $A$ and $B$ in Figure 4, as

\footnotetext{
5 Because of the insolubility of inulin it is advisable to keep the urine flow above $1.0 \mathrm{cc}$. per minute, or to reduce considerably the plasma concentration of inulin.
}

representing the approximate relationship in the normal human kidney of urea reabsorption to the inulin $U / P$ ratio at values of the latter ranging from 1 to 200 (i.e., at urine flows between 122 and 0.6 cc. per minute).

\section{Physiological basis of urea reabsorption}

There is no evidence that urea is actively reabsorbed in any mammal; such active reabsorption is known to occur in the elasmobranch fishes, where the concentration of urea in the blood is very high (2000 to $3000 \mathrm{mgm}$. per cent), the concentration in the urine is invariably less than in the blood, and the concentration in the urine may rise and approach the concentration in the blood during diuresis. But in the elasmobranch fishes a special segment of the tubule, not present in other vertebrates, is apparently responsible for this active reabsorption (31). All the evidence in the mammals points to the conclusion that urea is reabsorbed passively, however multiform or complex this reabsorption; and, indeed, it appears that this reabsorption can be explained entirely by diffusion in consequence of a concentration gradient established by the reabsorption of water, providing it is assumed that the reabsorption of water takes place in at least two stages and at different loci in the tubule.

Although present methods do not afford a means of distinguishing separate processes of water reabsorption, Smith (33) has suggested that at least two such processes exist. One consists of the isosmotic reabsorption of water in the proximal tubule, which is accompanied by, or made possible by, the simultaneous reabsorption of chloride, glucose, and other substances. Since this process accounts for about $100 \mathrm{cc}$. out of the 120

Fig. 4. (Above) 225 Observations on 10 Normal Subjects at Urine Flows from 20 down to 0.5 cc. per Minute (the Normal Range of Diuresis)

Line $B:$ the best straight line through these data. Line $A$ : the relationship to be expected at urine flows of 20 to 122 cc. per minute, based on observations on the dog (29).

It is suggested that line $A$ represents one reabsorptive process related to the obligatory reabsorption of water in the proximal segment, and line $B$ a second reabsorptive process related to the facultative reabsorption of water in the thin limb and distal segment. The former process cannot be abolished in the normal kidney by water diuresis.

(Below) 167 ObServations on 22 SubJects with Glomerulonephritis

Lines $A$ and $B$ as described above. At any given inulin U/P ratio, the fraction of urea reabsorbed is essentially the same in the nephritic kidney at all stages of the disease as in the normal. Partial impairment of the obligatory reabsorption of water at a time when facultative reabsorption is still present tends to obliterate the angle between $A$ and $B$. 
cc. of glomerular filtrate which is never excreted by the normal kidney, Smith called it the "obligatory" reabsorption of water. The second process of water reabsorption appears to occur in the distal portions of the tubule; it is in this process that the final urine is concentrated and raised to osmotic pressures greater than the blood, and since it is by variations in this process that the rate of water excretion (urine flow) is controlled, the process was designated as "facultative" reabsorption.

We are inclined to attribute that moiety of urea reabsorption (30 to 40 per cent) which occurs at inulin $U / P$ ratios of 10 to the obligatory reabsorption of water, and the further reabsorption of urea at inulin $U / P$ ratios above 10 to the facultative reabsorption of water. In doing so, we are joining with Shannon (29) in a similar identification in the dog. Since the obligatory reabsorption of water cannot be reduced by water diuresis in normal man (i.e., the inulin $\mathrm{U} / \mathrm{P}$ ratio cannot be lowered much below 10), the urea clearance cannot be raised by water diuresis higher than about 70 per cent of the filtration rate.

It must be recognized that a reduction in the filtration rate, whether resulting from lowered arterial pressure, oligemia, or other causes, can lead to an increased reabsorption of urea, possibly because it prolongs the time for diffusion (27). Variations in the filtration rate relative to the mass of normal tubular tissue, together with variations in the obligatory reabsorption of water, may in part account not only for the scatter of the data in Figure 4, but also for the elevation of the urea clearance on rising urine flows, as illustrated in Figure 3, and the apparently excessive depression of the urea/inulin clearance ratio at high inulin $U / P$ ratios in both normal and nephritic subjects. Although of considerable importance, it is impossible at the present time, and unnecessary for our present purposes, to treat these aspects of the problem quantitatively.

\section{Inulin and urea clearances in subjects with glomerulonephritis}

We present 167 simultaneous urea and inulin clearances in 22 subjects, 7 of whom were examined during a first attack of diffuse glomerulonephritis and 15 in the chronic stage. Some of the latter were examined during an acute exacerbation. There appears to be no necessity for considering these subjects in detail; essential data are given in Table I, and the urea/inulin clearance ratio in relation to the inulin $U / P$ ratio is presented in the lower part of Figure 4.

It is to be noted that our observations on subjects with glomerulonephritis have all been made under conditions of water plethora, and on the descending limb or close to the peak of maximal water diuresis. Our data are therefore of such a nature as to reveal a change in the minimal inulin $\mathrm{U} / \mathrm{P}$ ratio.

It is immaterial to this discussion whether or not the urine during maximal diuresis is dilute, in the sense of having a low specific gravity, since the specific gravity depends upon the variable reabsorption of chloride, glucose, and other substances. The important point is the extent to which the glomerular filtrate is concentrated by the obligatory reabsorption of water.

As said above, in the normal subject the minimal inulin $U / P$ ratio has never been observed to fall below 6 , and it frequently cannot be reduced below 10. This is in sharp contrast to the nephritic kidney in which the reabsorptive function of the tubule has been impaired by disease. Reference to the mass plot in the lower part of Figure 4 shows that, with advancing destruction of renal tissue, the minimal inulin $\mathrm{U} / \mathrm{P}$ ratio falls, and ultimately reaches such low values as 2.0 . It must be concluded from this fact that during the course of disease the obligatory reabsorption of water is for some reason impaired. In advanced nephritis there is frequently a continuous excretion of base and chloride, ${ }^{6}$ and it is possible that it is the failure of electrolyte reabsorption and related processes that leads, by osmotic ob-: struction, to reduction in the obligatory reabsorption of water. But whatever the cause, as the minimal inulin $U / P$ ratio falls from 10 to 2 , the reabsorption of urea decreases and the urea/inu-

\footnotetext{
6 This circumstance perhaps contributes to the fixed specific gravity of the urine, characterized clinically as isosthenuria. Our observations were not designed to examine the effect of disease upon the facultative reabsorption of water (i.e., the production of a hypertonic urine); it is presumably the failure of this process that leads to the clinical conditions of polyuria and hyposthenuria.
} 
TABLE I

Inulin and urea clearances in subjects with acute or chronic diffuse glomerulonephritis

\begin{tabular}{l|c|c|c|c}
\hline \hline Subject & $\begin{array}{c}\text { Days } \\
\text { after } \\
\text { first } \\
\text { observa- } \\
\text { tion }\end{array}$ & Plasma urea & \multicolumn{2}{|c|}{$\begin{array}{c}\text { Clearance* } \\
\text { per } 1.73 \text { 8q. m. }\end{array}$} \\
\hline & Inulin & Urea \\
\hline & $\begin{array}{c}\text { mgm. } \\
\text { per cent }\end{array}$ & $\begin{array}{c}\text { cc. per } \\
\text { minute }\end{array}$ & $\begin{array}{c}\text { cc. per } \\
\text { minute }\end{array}$ \\
\hline
\end{tabular}

ACUTE DIFFUSE GLOMERULONEPHRITIS

\begin{tabular}{|c|c|c|c|c|}
\hline 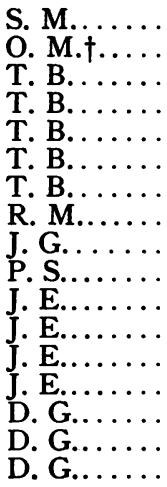 & $\begin{array}{r}5 \\
5 \\
12 \\
35 \\
5 \\
21\end{array}$ & $\begin{array}{l}62.3 \\
40.4 \\
69.0 \\
50.4 \\
55.1 \\
44.7 \\
41.1 \\
30.2 \\
27.5 \\
33.6 \\
17.1 \\
18.5 \\
20.4 \\
22.5 \\
34.6 \\
33.3 \\
23.7\end{array}$ & $\begin{array}{r}57.6 \\
71.9 \\
46.2 \\
61.3 \\
61.6 \\
71.1 \\
81.9 \\
97.9 \\
108.2 \\
88.3 \\
130.6 \\
118.3 \\
122.1 \\
122.3 \\
89.1 \\
88.5 \\
117.8\end{array}$ & $\begin{array}{l}31.3 \\
43.0 \\
26.6 \\
45.4 \\
44.2 \\
47.5 \\
55.7 \\
57.2 \\
64.4 \\
35.8 \\
59.1 \\
57.9 \\
62.2 \\
58.9 \\
39.5 \\
39.6 \\
68.7\end{array}$ \\
\hline
\end{tabular}

CHRONIC DIFFUSE GLOMERULONEPHRITIS

\begin{tabular}{|c|c|c|c|c|}
\hline 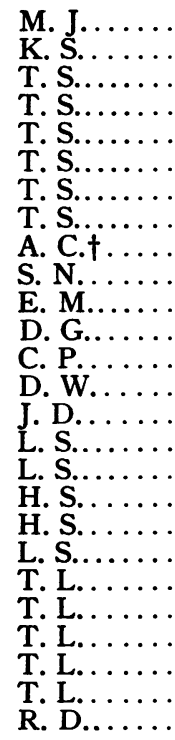 & $\begin{array}{r} \\
12 \\
365 \\
\\
6 \\
240 \\
256 \\
334\end{array}$ & $\begin{array}{r}37.2 \\
75.7 \\
254.6 \\
266.0 \\
292.0 \\
301.0 \\
387.5 \\
421.0 \\
98.7 \\
34.5 \\
125.0 \\
23.6 \\
153.9 \\
298.0 \\
142.2 \\
18.1 \\
21.1 \\
87.6 \\
228.2 \\
145.4 \\
70.0 \\
66.0 \\
72.4 \\
70.0 \\
81.4 \\
40.3\end{array}$ & $\begin{array}{r}28.8 \\
17.3 \\
4.4 \\
4.5 \\
4.7 \\
4.9 \\
4.8 \\
3.5 \\
9.8 \\
49.6 \\
13.6 \\
136.3 \\
18.4 \\
5.5 \\
13.8 \\
105.6 \\
143.5 \\
15.8 \\
6.2 \\
13.9 \\
60.8 \\
66.7 \\
22.2 \\
21.8 \\
17.5 \\
72.4\end{array}$ & $\begin{array}{c}23.2 \\
14.7 \\
3.4 \\
3.8 \\
3.7 \\
4.1 \\
4.0 \\
2.8 \\
7.9 \\
34.2 \\
10.0 \\
64.5 \\
14.7 \\
4.7^{\star} \\
11.4 \\
45.4 \\
60.6 \\
12.5 \\
5.4 \\
10.7 \\
31.4 \\
32.9^{*} \\
15.1^{*} \\
15.5^{*} \\
13.6^{*} \\
57.5\end{array}$ \\
\hline
\end{tabular}

† These subjects were in congestive heart failure at the time of examination. Their urea/inulin clearance ratios in relation to the inulin $U / P$ ratios were in agreement with all the other subjects studied.

Each clearance figure is the average of four consecutive urine collection periods with average urine volume of 1.0 to $1.5 \mathrm{cc}$. per minute where marked ${ }^{*}$, otherwise above $1.5 \mathrm{cc}$. per minute. lin clearance ratio rises towards 1.0 along the general course indicated by line $\mathrm{A}$. In short, at any given inulin U/P ratio the reabsorption of urea proceeds in the nephritic kidney just as it would in the normal kidney.

Certain apparent exceptions to this statement are, we believe, subject to explanation. The data on the nephritic kidney are not distributed in two distinct relationships $(A$ and $B)$ in Figure 4, but fall with fair uniformity along a single rectilinear relationship. This transposition is to be expected if impairment of the obligatory reabsorption of water (which would lead to movement upward along line $A$ ) occurs at a time when the facultative reabsorption (which leads to movement to the right along line $B$ ) is still capable of concentrating the urine. Hence an early reduction in the obligatory reabsorption of water would tend to obliterate the angle between line $A$ and $B$. The tendency of the data to fall below line $B$ at high inulin U/P ratios may be associated with a reduction in filtration rate, either due to prerenal deviation of water or glomerular dysfunction, at a time when the mass of functional tubules is still essentially normal.

The above interpretation rests upon the assumption that the inulin clearance is a trustworthy index of the rate of glomerular filtration in the nephritic kidney. It might be argued that, even though there is no reabsorption of inulin in the normal kidney, such reabsorption occurs in the nephritic kidney, and that the convergence of the urea and inulin clearances in the latter is a result of the simultaneous diffusion of these substances out of the tubular urine. Against this belief there may be advanced the facts that the diffusion coefficient of urea is seven times as great as that of inulin (4), and the difference in penetrating power must be even greater where protoplasmic barriers are involved. The normal tubule is apparently impermeable to inulin, and its permeability to urea (one of the most diffusible substances so far as living tissues are concerned) is of a very low order. If an increase in permeability occurred, urea should escape first, and seven times as rapidly, as inulin, and the fraction of urea reabsorbed should show a detectable increase. Moreover, the urea/inulin clearance ratio should decrease more rapidly, with increasing inulin $U / P$ ratio, in the nephritic kidney than it does in the 


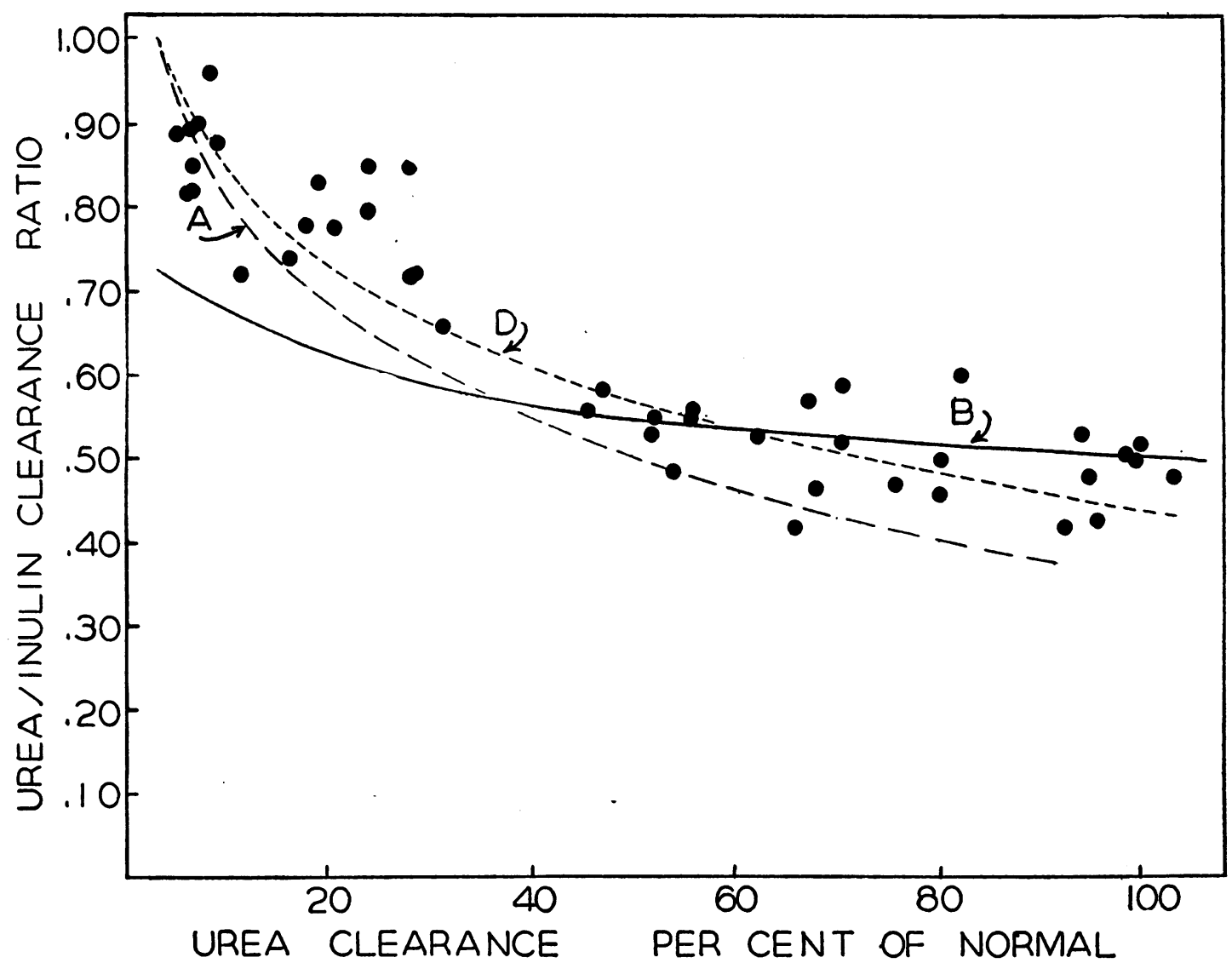

Fig. 5. The Urea Clearance When $V=2.0 \mathrm{cc}$. Per Minute (43 Observations) in 22 SubJects WITH GLOMERULONEPHRITIS

Since the value of the urea clearance depends on the urine volume, the use of unselected urea clearances for the above comparison introduces unnecessary deviation, and for the construction of this figure we have first plotted all our urea clearances against the urine flow. Treating each group of subjects having approximately the same inulin clearance separately, we have drawn smooth curves through the resulting scatter diagram and from these curves interpolated the value of the urea clearance for each subject when the urine flow is $2.0 \mathrm{cc}$. per minute. In the early stages of disease the urea clearance ( $V$ $=2.0$ cc. per minute) has an average value of 50 per cent of the inulin clearance; as renal impairment progresses it rises to 90 per cent of the inulin clearance. Lines $A$ and $B$ show the relationships calculated from the corresponding lines in Figure 4. Line $D$ (not shown in Figure 4) is the relationship calculated from a single median line through all the data on nephritics, as shown in that figure.

normal. All the data are contrary to these expectations. In our series we have not observed a nephritic subject, such as has been reported by others $(14,2,5,39)$, in whom the urea clearance falls to low values relative to the glomerular clearance. It may be that in such subjects the glomerular clearance is abnormally high, that the filtration rate relative to the residual functional tubular tissue is abnormally low, or that unusual reabsorption of urea occurs by the mechanism responsible for the transient, complete reabsorption which has been reported in the $\operatorname{dog}(11,37)$.
But insofar as the subjects examined by us are typical of the course of glomerulonephritis, it is clear that the reabsorption of urea decreases progressively as glomerular function is reduced. The practical significance of this fact is effectively illustrated in Figure 5, where the urea/inulin clearance ratio in the nephritic subjects examined here is plotted against the urea clearance expressed as per cent of the normal value.

7 The tendency of the creatinine and urea clearances to converge in advanced nephritis is evident in the reports 
The above facts are clearly contrary to the view that the elevation of the blood urea in glomerulonephritis is owing to increased reabsorption of urea. Our results indicate that this elevation is owing to decreased filtration, with actually decreased reabsorption. In principle, it appears that the blood urea, all other things being equal, should vary inversely as the urea clearance; such an inverse relationship is adequately demonstrated by the well known scatter diagrams relating the blood urea to the urea clearance which have been presented by MacKay and MacKay (18) and Van Slyke, McIntosh, Möller, Hannon and Johnston (35).

\section{"Standard" and "maximum" urea clearances}

Inspection of Figures 1 and 2 shows that our data conform roughly to the "standard" and "maximum" clearance concept of Möller, McIntosh and Van Slyke (20). In the light of the further analysis submitted here, however, it is clear that the standard clearance is an approximation, while the "maximum" clearance neglects the effect of urine flow on the reabsorption of urea at inulin U/P ratios below 60 . But since the effect of urine flow is slight when the latter is $2.0 \mathrm{cc}$. or above, it appears advisable in the interests of simplicity to adhere to the uncorrected clearance in utilizing the excretion of urea as an index of renal function. It is not possible, from our present data, to comment on the accuracy of the use of $\sqrt{V}$ in the calculation of the " standard" clearance, but it would seem advisable for physiological reasons to maintain the urine flow above $1.5 \mathrm{cc}$. wherever possible, since at flows below that level complicating factors (dehydration, lowered filtration rate, etc.) may vitiate any empirical mathematical correction.

of several observers, and has been commented upon by Winkler and Parra (39). This convergence is explicable in terms of decreased reabsorption of urea due to reduction in the degree of concentration of the glomerular filtrate. There is no evidence that the permeability of the glomerular membranes is reduced in nephritis in such a manner as to prevent the free filtration of inulin but not urea. The continued excretion of albumin, the convergence of the creatinine and urea clearances, and the fact that the urea clearance never exceeds the inulin clearance may be advanced as arguments against this supposition.

\section{SUM M ARY}

The urea clearance has been examined in 10 normal subjects and 22 subjects with glomerulonephritis, with special reference to the degree of concentration of the glomerular filtrate as indicated by the simultaneous inulin $U / P$ ratio.

Urea is invariably reabsorbed to some extent from the glomerular filtrate, whether this is at the normal level or is reduced by disease. This reabsorption is interpreted in terms of an hypothesis, based upon independent evidence, in which it is posited that water reabsorption occurs in two stages, one in the proximal tubule and one in the thin limb and distal tubule.

At any inulin $\mathrm{U} / \mathrm{P}$ ratio (i.e., degree of concentration of the glomerular filtrate) the reabsorption of urea proceeds in the nephritic kidney essentially as it would in the normal kidney. As the capacity to reabsorb water is impaired by disease, the fraction of urea reabsorbed decreases, so that the urea clearance approaches the rate of glomerular filtration.

In none of the subjects examined was there evidence of increased back-diffusion of urea, the elevation of the blood urea in nephritis being a result solely of the reciprocal relationship between this term and the urea clearance, as expected in principle.

\section{BIBLIOGRAPHY}

1. Alving, A. S., and Gordon, W., Studies of urea, creatinine and ammonia excretion in dogs in acidosis. J. Biol. Chem., 1937, 120, 103.

2. Bing, J., and Bjering, T., Individual variations in the relation between urea clearance and creatinin clearance. Acta. med. Scandinav., 1937, 93, 318.

3. Bjering, T., Hvilken nyrefunktionspr $\phi$ ve vor foretraekkes i фjeblikket? (Sammenligmende undusфgelser over urinstof "Clearance," og "Filtration" hos Pp. med nefritis.) Nordisk. Med. tidskr., 1934, 8, 1397.

4. Bunim, J. J., Smith, W. W., and Smith, H. W., The diffusion coefficient of inulin and other substances of interest in renal physiology. J. Biol. Chem., 1937, 118, 667.

5. Cambier, P., Application de la théorie de Rehberg à l'étude clinique des affections rénales et du diabete. II. La fonction rénale chez les sujets normaux et chez les néphrétiques. Ann. de méd., 1934, 35, 196.

6. Cope, C. L., The excretion of creatinine by the human kidney in health and in nephritis. Quart. J. M., 1931, 24, 567. 
7. Covian, F. G., and Rehberg, P. B., Uber die Nierenfunktion während schwerer Muskelarbeit. Skandinav. Arch. f. Physiol., 1936, 75, 21.

8. Ellis, L. B., and Weiss, S., Normal variations in renal function tests with discussion of their physiologic significance. Am. J. M. Sc., 1933, 186, 233.

9. Ellis, L. B., and Weiss, S., Renal function in arterial hypertension. J. A. M. A., 1933, 100, 875.

10. Goldring, W., and Smith, H. W., Differentiation of glomerular and tubular function in glomerular nephritis. Proc. Soc. Exper. Biol. and Med., 1937, 37, 180.

11. Gordon, W., Alving, A. S., Kretzschmar, N. R., and Alpert, L., Variations in the extraction of urea by the kidney and their relation to the amount of urea reabsorbed. Am. J. Physiol., 1937, 119, 483.

12. Hayman, J. M., Jr., Halsted, J. A., and Seyler, L. E., A comparison of the creatinine and urea clearance tests of kidney function. J. Clin. Invest., 1933, $12,861$.

13. Holten, C., and Rehberg, P. B., Studies on the pathological function of the kidneys in renal disease, especially Bright's disease. I. Acta med. Scandinav., 1931, 74, 479.

14. Holten, C., and Rehberg, P. B., Studies on the pathological function of the kidneys in renal disease, especially Bright's disease. II. Acta. med. Scandinav., 1931, 74, 538.

15. Iversen, $P$., and Bjering, $T$., Is the creatinine clearance an expression of filtration through the glomeruli? Acta. med. Scandinav., 1935, 86, 458.

16. Jolliffe, N., and Smith, H. W., The excretion of urine in the dog. I. The urea and creatinine clearances on a mixed diet. Am. J. Physiol., 1931, 98, 572.

17. MacKay, E. M., and Cockrill, J. R., The regulation of renal activity. XII. The relation of the rate of creatinine excretion in the urine to the plasma concentration. Am. J. Physiol., 1930, 94, 220.

18. MacKay, E. M., and MacKay, L. L., The relation between the blood urea concentration and the amount of functioning renal tissue. J. Clin. Invest., 1927, 4, 127.

19. Mayrs, E. B., The relative excretion of urea and some other constituents of the urine. J. Physiol., 1922, 56, 58.

20. Möller, E., McIntosh, J. F., and Van Slyke, D. D., Studies in urea excretion. II. Relationship between urine volume and the rate of urea excretion by normal adults. J. Clin. Invest., 1928, 6, 427.

21. Peters, J. P., Wakeman, A. M., and Lee, C., Total acid-base equilibrium of plasma in health and disease. XI. Hypochloremia and total salt deficiency in nephritis. J. Clin. Invest., 1929, 6, 551.

22. Pitts, R. F., The comparison of urea with urea + ammonia clearances in acidotic dogs. J. Clin. Invest., 1936, 15, 571 .
23. Pitts, R. F., and Korr, I. M., The excretion of urea in the chicken. J. Cell. and Comp. Physiol., 1938, 11, 117.

24. Rehberg, P. B., Studies on kidney function. I. The rate of filtration and reabsorption in the human kidney. Biochem. J., 1926, 20, 447.

25. Rehberg, P. B., Studies on kidney function. II. The excretion of urea and chlorine analysed according to a modified filtration-reabsorption theory. Biochem. J., 1926, 20, 461.

26. Shannon, J. A., The renal excretion of creatinine in man. J. Clin. Invest., 1935, 14, 403.

27. Shannon, J. A., Glomerular filtration and urea excretion in relation to urine flow in the dog. Am. J. Physiol., 1936, 117, 206.

28. Shannon, J. A., Excretion of inulin, creatinine, xylose and urea in the sheep. Proc. Soc. Exper. Biol. and Med., 1937, 37, 379.

29. Shannon, J. A., The excretion of urea in the dog at high urine flows. Am. J. Physiol., 1938 (In press).

30. Shannon, J. A., and Smith, H. W., The excretion of inulin, xylose and urea by normal and phlorizinized man. J. Clin. Invest., 1935, 14, 393.

31. Smith, H. W., The retention and physiological role of urea in the elasmobranchii. Biol. Rev., 1936, 11, 49.

32. Smith, H. W., The composition of urine in the seal. J. Cell. and Comp. Physiol., 1936, 7, 465.

33. Smith, H. W., The Physiology of the Kidney. Oxford University Press, New York, 1937.

34. Smith, H. W., Goldring, W., and Chasis, H., The measurement of the tubular excretory mass, ef fective blood flow and filtration rate in the normal human kidney. J. Clin. Invest., 1938, 17, 263.

35. Van Slyke, D. D., McIntosh, J. F., Möller, E., Hannon, R. R., and Johnston, C., Studies of urea excretion. VI. Comparison of the blood urea clearance with certain other measures of renal function. J. Clin. Invest., 1930, 8, 357.

36. Van Slyke, D. D., Page, I. H., Hiller, A., and Kirk, E., Studies of urea excretion. IX. Comparison of urea clearances calculated from the excretion of urea, of urea plus ammonia, and of nitrogen determinable by hypobromite. J. Clin. Invest., 1935, 14, 901.

37. Van Slyke, D. D., Rhoads, C. P., Hiller, A., and Alving, A. S., Relationships between urea excretion, renal blood flow, renal oxygen consumption and diuresis. The mechanism of urea excretion. Am. J. Physiol., 1934, 109, 336.

38. Winkler, A. W., and Parra, J., The measurement of glomerular filtration. Creatinine, sucrose and urea clearances in subjects without renal disease. $J$. Clin. Invest., 1937, 16, 859.

39. Winkler, A. W., and Parra, J., The measurement of glomerular filtration. The creatinine, sucrose and urea clearances in subjects with renal disease. $\mathrm{J}$. Clin. Invest., 1937, 16, 869. 